\title{
Internal Operating Environment, Forecasting Techniques and Accuracy of Performance Forecasting
}

\author{
E. W. Chindia \\ School of Business \\ College of Humanities \& Social Sciences \\ Department of Management Science \\ University of Nairobi. Kenya.
}

\begin{abstract}
This article examines the influence of the internal operating environment (IOE) on the accuracy of performance forecasting (APF) in large manufacturing firms (LMFs) in Kenya. The objective of this project was to assess if any aspects of the IOE influenced measures of APF. APF, in manufacturing operations, is seldom derived accurately due to internal conflicts of interest. However, since LMFs hire skilled personnel, this study assumes that the qualified forecasting staff ensures accuracy in forecasts when preparing future budgets. IOE is said to influence the behavior of operations resulting in either adverse or favorable organizational performance. This study identified IOE factors that impact firm performance and tested these against measures of APF. Regression analysis was applied using data collected through a structured questionnaire administered among randomly selected LMFs. Results indicated that there was no evidence that IOE had an influence on APF, but it had a moderating effect on the relationship between the objective forecasting technique and APF through return on sales (ROS).
\end{abstract}

KeyWords: Internal operating environment, Accuracy of performance forecasting, large manufacturing firms, forecasting techniques.

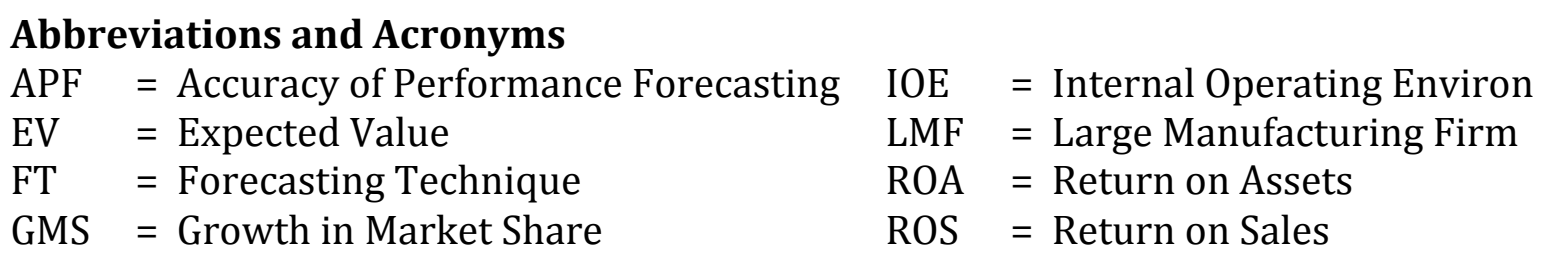

\section{INTRODUCTION}

While not always possible, it is often remarkable how much can be gleaned about a company's problems from internal and external audits, consultants' reports, financial numbers, newspaper and magazine articles, reporting on internal management weaknesses, staff attitudes, competitors and attitudes of customers. Very often the simple act of compiling the data from these separate sources can give a substantial amount of previously unseen insights into the problems a company suffers. The immediate step, therefore, is to detect the failure and then to analyze its causes, but hardly do company executives look at problems that inaccurate forecasting introduces in their businesses and elements of the internal environment that hamper precision in accurately assessing the future.

APF ensures the establishment and delivery of expected revenue and profitability goals of a firm. It is an integrated exercise in which all organizational operations at all levels should be involved and share information. This helps in increasing demand visibility as well as improving 
the performance of forecasts. Firms that apply forecasting appropriately and successfully have developed not only cross-functional trust, but also cross-organizational trust with suppliers of raw materials and distributors of finished products. However, many LMFs, in Kenya, still have a disconnect between the different functional areas involved in forecasting, which creates disruption in the supply chain process, ultimately adversely impacting the firms' ability to deliver products to its customers on time, in the right quantity and of the right quality. Forecasting in most LMFs is still handled without accurate supporting data or automation. In addition, most of the LMFs do not monitor their own forecasting accuracy at the beginning, during and at the end of a forecast period. Further, a number of the LFMs fail to grasp how gross margin - an import aspect of firm performance - is affected by poor forecasting.

While causes of decline in the performance of any business may include external environmental factors such as commodity price shocks, political interventions, technology changes and low-cost foreign competition, the impact of the internal operating environment can be deleterious. A number of the characteristics of management that cause terminal decline in many firms are virtually indistinguishable from those that are responsible for success in a large number of organizations. Inappropriate management tends to kill companies. What constitutes appropriate management changes significantly during the life cycle of a company or even product, most notably when it comes under competitive threat, including poor control systems, cost slippage and staff attitudes towards consumers. Accuracy in forecasting future performance of a business therefore, constitutes an internal environmental factor that can lead to success or failure.

Forecasting therefore, remains a key fundamental in predicting the future performance of any industry as managers grapple to understand about the future before it happens. Consequently, accurate forecasting can help in developing strategies to promote profitable trends and to avoid unprofitable ones. This study tested the strength of the influence of the internal operating environment as relates to APF in LMFs, in Kenya.

\section{LITERATURE REVIEW}

Businesses, on the whole, use forecasting as a tool to predict the future. While it is an essential aspect in the management of business, its accuracy and application have always posed challenges for decision-makers, including the fact that there is no one foolproof and accurate way of forecasting. Berinato (2001), Fildes \& Hastings (1994) observe that "since individuals are often involved in forecast formulation and implementation they can influence how the forecasts are employed". On their part, Bails \& Peppers (1982) and Adebanjo \& Dotun (2000) posit that "demand forecasts are necessary since the basic operations process takes time". In any operations process, the success or otherwise of the operations depends on the manager's leadership style, strategy formulated for the operations, structure in terms of how operations are integrated and the culture that has been cultivated over time. Consequently, the internal operating environment for this study includes the above factors - leadership, strategy, structure and culture - that will be tested for their interaction effect with APF. According to Khandwalla (1977), organizational performance is enhanced when there is a good 'fit' between management style and various contextual factors, which include leadership, strategy, structure and organizational culture and can be measured through market share, customer satisfaction, corporate image, profitability and organizational growth.

Researchers have defined strategy differently, but with the same logic of planning for superior performance. Mintzberg and Quinn (1996) defined strategy as "the plan that integrates an organization's major goals, policies, and action sequences into a cohesive whole". Thompson 
and Strickland (1993) defined strategy as "the pattern of organizational moves and managerial approaches used to achieve organizational objectives and to pursue the organization's mission". On his part, Porter (1996), states that "The essence of strategy is choosing to perform activities differently than rivals do". And, according to Zahra (1993), "a strategy offers a framework within which the company defines possible means for achieving goals". Much literature has emphasized the benefits of planning for the company's performance in a competitive environment.

On the other hand, organizational structure often refers to an organization's internal pattern of relationships, authority, and communication (Thompson, 1967). The hierarchical dimensions of structure, including, complexity, formalization and centralization have received more attention (Child, 1974; Ford and Slocum, 1977; Fry, 1982). Robins (2004) states that "formalization refers to an organization where there are explicit job descriptions, lots of organizational rules, and clearly defined procedures covering work processes". Smith and Mentzer (2010) observe that when companies develop and apply more accurate forecasts in their planning and management activities, they have the potential to improve performance throughout their organization and across the supply chain. To realize these improvements, however, companies must implement techniques and practices that improve forecast accuracy, and integrate the more accurate forecasts into their planning and management activities.

Johnson \& Scholes (1984) defined corporate culture as being the deeper level of basic values, assumptions and beliefs that are shared by members of an organization'. These norms govern the behavior of people within the company and are reflected within an organizational culture and manifested through the rites, rituals and routines that take place within an organization, the language used, the stories, legends and myths that are told and re-told, the symbols, logos and artifacts that are found throughout the company. According to Maull et al (2001) "culture is taught to new members as the correct way to behave, thus perpetuating organizational survival and growth. Any deviation from the culture can result in a dysfunctional entity and may affect the performance of the company". This assertion appears to manifest in monopolistic entities with little competitive threats. Such organizations are generally unwilling to change to confront a dynamic business environment. These types of organizations usually maintain a steady stream of clients who have no alternative choices for their product needs. The organizations can, therefore, accurately forecast their performance with little effort and controversy. In recent times, the disdain by youthful and more qualified and inquisitive employees against a perpetuated organizational culture by the older workers, who have embraced certain aspects of culture blindly without questioning, is resulting in a revolution that is creating more leaders than followers, and ultimately, better forecasters.

Vecchio \& Appelbaum (1995) view leadership as a process through which a person tries to get others in the organization to do what he or she wants. Sleath et al. (1996) state that actions that link people and tasks to accomplish work are what leadership is. Aosa (1998) observed that leadership is the ability to influence others to strive towards achieving organizational objectives by mobilizing and showing people the way forward. Allen \& Kraft (1987) defined successful leadership as the ability to bring about sustained culture change. They posit that a leader has the responsibility for allocating tasks, duties, structuring the organization and distributing materials and financial resources. In today's global market that is more volatile, unpredictable, uncertain, complex and ambiguous than ever before, it is crucial to have strong and capable leadership in these times of exponential change. Leaders are those who empower others and often go out there to make it happen. In every case leadership is the capacity to transform vision into reality and the managers are the moral leaders who ensure performance 
with integrity. Some top world business leaders have observed that "the function of leadership is to produce more leaders and not followers; and that outstanding leaders go out of their way to boost the self-esteem of their personnel, that is, if people believe in themselves, it's amazing what they can accomplish".

Forecast accuracy tends to deteriorate when forecasting teams use poor data quality; the leader's ethical and professional decision-making are in conflict - there is a mismatch between what they see and how they make sense of the data provided; effects of self-awareness of empowering and transformational leadership; and installing a collaborative forecasting support supply chain management. When a leader's needs and wishes diverge from those of constituents, the consequences can be quite disastrous. Further, the dangers that leaders will surround themselves with "yes men" and thus fail to discern the correct picture of the forecasts can result in organizational poor performance. In addition, organizational impact of system quality, information quality and service quality remain the leader's areas of concern. This study views a leader as a change agent who can influence accuracy of performance forecasting in an organization.

In summary, this study has demonstrated that the IOE has an influence on the type of forecasting strategy a LMF may adopt and can also impact forecast accuracy as it has a moderating effect on the relationship between a FT and APF.

\section{CONCEPTUAL FRAMEWORK}

APF can be viewed as a subset of the larger notion of corporate performance. According to Fahy \& Smithee (1999), forecasting models are conceptualized on the premise that the desired outcome of organizations is to achieve a sustainable competitive advantage that allows them to earn above-average returns. This research study demonstrates two findings: that the IOE has an influence on APF; that the IOE has a moderating effect on the relationship between a FT and APF. A moderator variable is a third variable that affects the strength of the relationship between a dependent and independent variable in correlation. The conceptual framework, Figure 1, displays the linkages in the variables of interest for this study whose results showed that the different forecasting techniques had an influence on some measures of accuracy of performance forecasting in varying degrees. The study also revealed that the IOE had a moderating effect on the relationship between a FT and APF.

Figure 1 Conceptual Framework

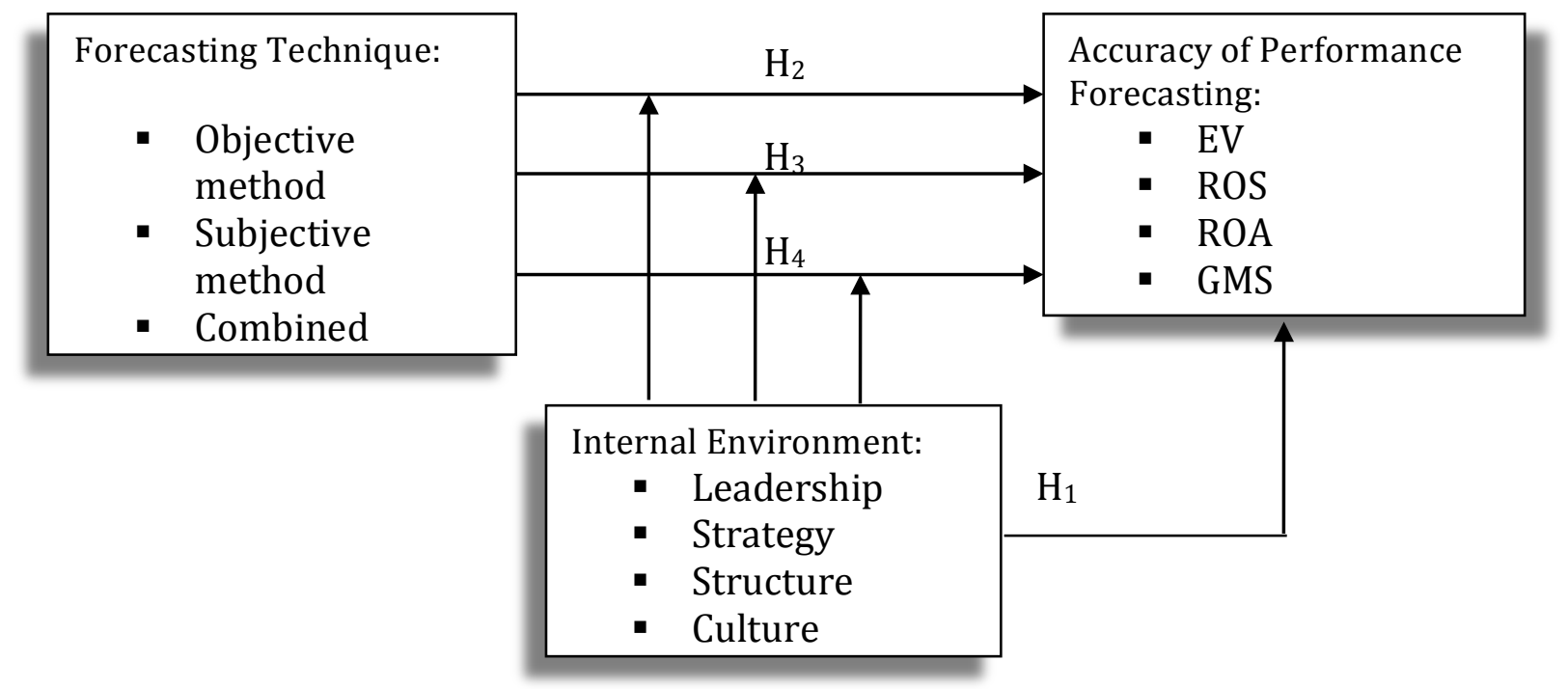




\section{Indicators of Accuracy of Performance Forecasting}

The following dependent variables of accuracy of performance forecasting were used in this study:

\section{Profit Growth (PG)}

Profit growth (PG) is often called Expected Value (EV), which is a measure of a firm's growth in profit year-on-year computed in real terms to eliminate distortions introduced by fluctuations in currencies. The EV gives an indication of how a firm is managing costs while increasing prices at the same time even in a market with intense rivalry and diminishing purchasing power. If a firm's forecasts are unbiased and accurate the actual EV yield will approximate expected performance.

\section{Return on Sales (ROS)}

ROS is a ratio that is used to evaluate a company's operational efficiency. It can also be described as a firm's operating profit margin. It measures a company's performance by analyzing what percentage of total company revenues are actually converted into company profits. Mathematically, ROS is calculated by dividing the operating profit by the net sales for that period.

\section{Return on Assets (ROA)}

ROA demonstrates how profitable a company is relative to its total assets. It gives an indication as to how efficient management is at utilizing its assets to generate earnings. It is calculated by dividing a company's annual earnings by its total assets, and is generally displayed as a percentage.

\section{Growth in Market Share (GMS)}

Market share is the percentage of an industry or market's total sales that is earned by a particular company over a specified time period. Market share is calculated by taking the company's sales over the period and dividing it by the total sales of the industry over the same period. Growth in market share year-on-year indicates growth in sales of a company relative to the industry total. For example, if a company's sales were $S_{1}$ in period one and $S_{2}$ in period two while the industry total sales were $\mathrm{T}_{1}$ and $\mathrm{T}_{2}$ respectively, then growth in market share, as a ratio, would be computed as $\left(\mathrm{S}_{2}-\mathrm{S}_{1}\right) / \mathrm{T}_{2}$.

\section{HYPOTHESES}

H1: $\quad$ IOE has an influence on the APF in LMFs, in Kenya.

H2: $\quad$ IOE has a moderating effect on the relationship between a FT and APF in LMFs, in Kenya

\section{RESEARCH PROBLEM}

Over time, various research streams have offered a mixed picture of the extent that APF has improved in business forecasting; on the other hand empirical findings indicate that practice studies have not found evidence that industry is actually achieving improvement in APF. The research question which this study examines is: What is the influence of the IOE on APF and FTs in LMFs, in Kenya? The research focus included identifying APF predictors that are influenced by the IOE and also examining the impact of the IOE on the relationship between a FT and APF. 


\section{METHODOLOGY OF RESEARCH}

This was a descriptive cross-sectional survey that used the positivist research philosophy where the researcher was limited to data collection and interpretation through an objective approach, and research findings were observable and quantifiable.

\section{Sample of Research}

The sample frame comprised 487 LMFs with not less than 100 employees each. Branches of group companies, managed independently, were treated as stand-alone entities. In their survey on small-scale manufacturers in Kenya, Gray et al. (1996) classified LMFs as employers with at least 100 workers. Sample size was calculated using a table for sample size determination of a "known" population by Krejcie et al. (1970), which resulted in 217 firms that were surveyed having been selected using proportionate stratified random sampling (PRS) technique. Each target firm in each industry sector and geographical location was selected using simple random sampling (SRS) which has the least bias and offers the most generalizability, Sekaran (1992)

\section{Instrument and Procedures}

This was a cross-sectional survey that elicited secondary data from study subjects using a structured questionnaire. The questionnaire was hand-delivered to selected teams of managers within the chosen sample of 217 firms. Fully and properly completed questionnaires were received from 176 firms, which resulted in a response rate of 81 per cent [(176/217)*100\%]. Prior to administering the questionnaire, the research instrument had been piloted on ten LMFs, in two countries, to assist in identifying any ambiguous and unclear questions. Respondents were assured of confidentiality and anonymity of their responses and feedback on study results, if needed. Data collection included respondents either completing the questionnaire on their own or in the presence of the researcher or research assistant while in their respective locations. Secondary data involved collecting existing information on firm performance from published and unpublished reports over a period of one year in the different LMFs. These metrics addressed the objective of the study.

\section{Data Analysis}

The data was subjected to regression analyses to estimate the relationships among variables. Regression analysis is widely used for prediction and forecasting to understand which among the independent variables are related to the dependent variable, and to explore the forms of these relationships. Regression analysis can also be used to infer causal relationships between independent and dependent variables. APF was the dependent variable in this study.

\section{RESULTS}

H1: IOE influences APF. To test this hypothesis, four parameters of the IOE leadership, strategy, structure and culture were tested against each measure of performance EV, ROS, ROA and GMS. This hypothesis was split into four sub-hypotheses in order to test for each of the performance measures, separately.

H1a: IOE influences EV. The study used EV as the dependent variable against the four elements of IOE. Table 1 provided p-values that were greater than 0.05 . The high calculated p-values meant that there was statistically not significant evidence to state that the IOE influenced EV. Sub-hypothesis H1a was therefore, rejected and it was concluded that IOE did not influence EV. 
Table 1 Internal Operating Environment - Coefficients

\begin{tabular}{|cl|c|c|c|c|c|}
\hline \multirow{2}{*}{ Model } & \multicolumn{2}{|c|}{$\begin{array}{c}\text { Un-standardized } \\
\text { Coefficients }\end{array}$} & \multicolumn{2}{c|}{$\begin{array}{c}\text { Standardized } \\
\text { Coefficients }\end{array}$} & & \\
\cline { 3 - 5 } & & Beta & Std. Error & Beta & t-Value & P-Value \\
\hline & (Constant) & 1.938 & 0.792 & & 2.448 & 0.015 \\
& Leadership & -0.150 & 0.097 & -0.127 & -1.537 & 0.126 \\
& Strategy & 0.025 & 0.055 & 0.036 & 0.455 & 0.650 \\
& Structure & -0.105 & 0.109 & -0.078 & -0.965 & 0.336 \\
& Culture & 0.174 & 0.126 & 0.107 & 1.387 & 0.167 \\
\hline
\end{tabular}

Dependent Variable: Expected Value

H1b: IOE influences ROS. Using ROS as a performance measure against the four elements of the IOE, table 2 yielded p-values that were greater than 0.05 . The high calculated $p$-values meant that there was statistically not significant evidence to state that the IOE influenced ROS. Subhypothesis H1b was therefore, rejected and concluded that the IOE did not influence ROS.

Table 2 Internal Operating Environment - Coefficients

\begin{tabular}{|c|c|c|c|c|c|c|}
\hline \multirow{2}{*}{\multicolumn{2}{|c|}{ Model }} & \multicolumn{2}{|c|}{$\begin{array}{l}\text { Un-standardized } \\
\text { Coefficients }\end{array}$} & \multirow{2}{*}{$\begin{array}{c}\text { Standardized } \\
\text { Coefficients }\end{array}$} & \multirow[b]{2}{*}{$\mathrm{T}$} & \multirow[b]{2}{*}{$\mathrm{P}$-value } \\
\hline & & B & Std. Error & & & \\
\hline \multirow[t]{5}{*}{1} & (Constant) & 9.648 & 4.104 & & 2.351 & 0.020 \\
\hline & Leadership & 0.041 & 0.505 & 0.007 & 0.081 & 0.935 \\
\hline & Strategy & -0.434 & 0.284 & -0.122 & -1.530 & 0.128 \\
\hline & Structure & -0.211 & 0.563 & -0.031 & -0.375 & 0.708 \\
\hline & Culture & 0.454 & 0.652 & 0.054 & 0.696 & 0.487 \\
\hline
\end{tabular}

Dependent Variable: ROS

H1c: The IOE influences ROA. The study used ROA as the dependent variable against the four elements of the internal operating environment. Table 3 provided p-values that were greater than 0.05. The high calculated p-values meant that there was statistically not significant evidence to state that the IOE influenced ROA. Sub-hypothesis H1c was therefore, rejected and it was concluded that the IOE did not influence ROA.

Table 3 Internal Operating Environment - Coefficients

\begin{tabular}{|c|c|c|c|c|c|c|}
\hline \multirow{2}{*}{\multicolumn{2}{|c|}{ Model }} & \multicolumn{2}{|c|}{$\begin{array}{c}\text { Un-standardized } \\
\text { Coefficients }\end{array}$} & \multirow{2}{*}{$\begin{array}{c}\text { Standardized } \\
\text { Coefficients } \\
\text { Beta } \\
\end{array}$} & \multirow[b]{2}{*}{ t-Value } & \multirow[b]{2}{*}{ P-Value } \\
\hline & & Beta & Std. Error & & & \\
\hline \multirow[t]{5}{*}{1} & (Constant) & 3.718 & 2.340 & & 1.588 & 0.114 \\
\hline & Leadership & 0.417 & 0.288 & 0.121 & 1.449 & 0.149 \\
\hline & Strategy & -0.136 & 0.162 & -0.067 & -0.840 & 0.402 \\
\hline & Structure & -0.261 & 0.321 & -0.067 & -0.814 & 0.417 \\
\hline & Culture & -0.367 & 0.372 & -0.077 & -0.988 & 0.324 \\
\hline
\end{tabular}

Dependent Variable: ROA

H1d: IOE has an influence on GMS. The study used GMS as a performance measure against the four parameters of IOE. Table 4 yielded p-values that were greater than 0.05 . The high calculated p-values meant that there was statistically not significant evidence to state that the IOE influenced GMS. Sub-hypothesis H1d was therefore, rejected and concluded that IOE did not influence GMS. 
Table 4 Internal Operating Environment - Coefficients

\begin{tabular}{|ll|c|c|c|c|c|}
\hline \multirow{2}{*}{ Model } & & \multicolumn{2}{|c|}{$\begin{array}{c}\text { Un-standardized } \\
\text { Coefficients }\end{array}$} & $\begin{array}{c}\text { Standardized } \\
\text { Coefficients }\end{array}$ & & \\
\cline { 3 - 5 } & & Beta & Std. Error & Beta & t-Value & P-Value \\
\cline { 2 - 5 } & (Constant) & 64.569 & 16.931 & & 3.814 & 0.000 \\
& Leadership & -2.395 & 2.081 & -0.096 & -1.151 & 0.252 \\
& Strategy & -0.092 & 1.170 & -0.006 & -0.078 & 0.938 \\
& Structure & -2.188 & 2.323 & -0.077 & -0.942 & 0.348 \\
& Culture & -1.737 & 2.689 & -0.050 & -0.646 & 0.519 \\
\hline
\end{tabular}

Dependent Variable: Growth in market share

In all the four test cases - using leadership, strategy, structure and culture, as independent variables of IOE, and EV, ROS, ROA and GMS, as measures of performance (dependent variables) - it was found that IOE did not have any influence on APF. Therefore, hypothesis H1 was rejected, and concluded that the IOE did not influence APF in LMFs, in Kenya.

Part two of the study objective focused on assessing the moderating effect of IOE on the relationship between a FT and APF. The following hypothesis was tested:

H2: IOE has a moderating effect on the relationship between a FT and APF. This hypothesis was split into sub-hypotheses each one of which was tested by combining moderator variables of IOE (leadership, strategy, structure and culture) with each interaction variable (FT), and regressed against each of the predictor variables (EV, ROS, ROA and GMS). The statistical significance of the outcomes, when the moderator variable was introduced, signified a moderating effect of the moderator variable on the relationship between the interaction variable and predictor variable.

H2a: IOE has a moderating effect on the relationship between objective FT and EV. EV was regressed against the four elements of the IOE and objective FT. Table 5 generated p-values, none of which was found to be statistically significant at the 0.05 level of significance. Subhypothesis $\mathrm{H} 2 \mathrm{a}$ was therefore, rejected and concluded that IOE did not have a moderating effect on the relationship between objective FT and EV.

Table 5 Internal Operating Environment - Coefficients

\begin{tabular}{|ll|l|l|l|l|l|}
\hline \multirow{2}{*}{ Model } & \multicolumn{2}{|l|}{$\begin{array}{l}\text { Un-standardized } \\
\text { Coefficients }\end{array}$} & $\begin{array}{l}\text { Standardized } \\
\text { Coefficients }\end{array}$ & & \\
\cline { 2 - 4 } & Beta & Std. Error & Beta & t-Value & P-Value \\
\hline 1 & (Constant) & 1.731 & 0.816 & & 2.120 & 0.035 \\
& Leadership & -0.151 & 0.097 & -0.129 & -1.551 & 0.123 \\
& Strategy & 0.020 & 0.055 & 0.029 & 0.359 & 0.720 \\
& Structure & -0.108 & 0.109 & -0.081 & -0.994 & 0.322 \\
& Culture & 0.172 & 0.126 & 0.106 & 1.372 & 0.172 \\
& Objective method & 0.064 & 0.061 & 0.080 & 1.043 & 0.299 \\
\hline
\end{tabular}

Dependent Variable: Expected Value

H2b: IOE has a moderating effect on the relationship between objective FT and ROS. ROS was used as a performance measure and regressed against the four elements of the IOE and objective FT. The analysis of variance in table 6 gave coefficients of the variables where the objective FT was found to be statistically significant at $p=0.003$, where the level of significance is 0.05 . This resulted in the following relationship: 
Return on Sales $=15.008-0.979$ Objective Method

$$
\text { (0.001) (0.003) }
$$

This implied that a unit marginal change in the use of the objective forecasting method resulted in a decline of 0.979 units in ROS. Sub-hypothesis H2b was therefore, not rejected and concluded that IOE has a moderating effect on the relationship between objective FT and ROS.

Table 6 Internal Operating Environment - Coefficients

\begin{tabular}{|ll|l|l|l|l|l|}
\hline \multirow{2}{*}{ Model } & \multicolumn{2}{l|}{$\begin{array}{l}\text { Un-standardized } \\
\text { Coefficients }\end{array}$} & \multicolumn{2}{l|}{$\begin{array}{l}\text { Standardized } \\
\text { Coefficients }\end{array}$} & & \\
\cline { 2 - 5 } & & Beta & Std. Error & Beta & t-Value & P-Value \\
\hline 1 & (Constant) & 15.008 & 4.335 & & 3.462 & 0.001 \\
& Leadership & -0.024 & 0.517 & -0.004 & -0.047 & 0.962 \\
& Strategy & -0.118 & 0.292 & -0.032 & -0.405 & 0.686 \\
& Structure, & -0.237 & 0.577 & -0.033 & -0.411 & 0.681 \\
& Culture & 0.063 & 0.668 & 0.007 & 0.094 & 0.925 \\
& Objective method & -0.979 & 0.325 & -0.229 & -3.011 & 0.003 \\
\hline
\end{tabular}

Dependent Variable: ROS

H2c: IOE has a moderating effect on the relationship between objective FT and ROA. Table 7 displays coefficients of the variables where none of the p-values of the variables was statistically significant. Sub-hypothesis H2c was therefore, rejected and concluded that IOE has no moderating effect on the relationship between objective FT and ROA.

Table 7 Internal Operating Environment - Coefficients

\begin{tabular}{|ll|l|l|l|l|l|}
\hline \multirow{2}{*}{ Model } & \multicolumn{2}{|l|}{$\begin{array}{l}\text { Un-standardized } \\
\text { Coefficients }\end{array}$} & $\begin{array}{l}\text { Standardized } \\
\text { Coefficients }\end{array}$ & \multirow{2}{*}{} \\
\cline { 2 - 5 } & Beta & Std. Error & Beta & t-Value & P-Value \\
\hline & (Constant) & 3.911 & 2.420 & & 1.616 & 0.108 \\
& Leadership & 0.418 & 0.288 & 0.121 & 1.449 & 0.149 \\
& Strategy & -0.131 & 0.163 & -0.065 & -0.805 & 0.422 \\
& Structure, & -0.258 & 0.322 & -0.066 & -0.802 & 0.424 \\
& Culture & -0.366 & 0.373 & -0.077 & -0.981 & 0.328 \\
& Objective method & -0.060 & 0.181 & -0.025 & -0.328 & 0.743 \\
\hline
\end{tabular}

Dependent Variable: ROA

H2d: IOE has a moderating effect on the relationship between objective FT and GMS. Table 8 displays ANOVA coefficients of the variables, none of which was statistically significant. Subhypothesis $\mathrm{H} 2 \mathrm{~d}$ was therefore, rejected and concluded that IOE has no moderating effect on the relationship between objective FT and GMS. 
Table 8 Internal Operating Environment - Coefficients

\begin{tabular}{|ll|l|l|l|l|l|}
\hline \multicolumn{2}{|c|}{ Model } & \multicolumn{2}{|l|}{$\begin{array}{l}\text { Un-standardized } \\
\text { Coefficients }\end{array}$} & $\begin{array}{l}\text { Standardized } \\
\text { Coefficients }\end{array}$ & & \\
\cline { 3 - 5 } & & Beta & Std. Error & Beta & t-Value & P-Value \\
\hline & (Constant) & 66.306 & 17.503 & & 3.788 & 0.000 \\
& Leadership & -2.383 & 2.087 & -0.096 & -1.142 & 0.255 \\
& Strategy & -0.048 & 1.178 & -0.003 & -0.041 & 0.967 \\
& Structure, & -2.161 & 2.330 & -0.076 & -0.928 & 0.355 \\
& Culture & -1.721 & 2.696 & -0.050 & -0.639 & 0.524 \\
& Objective method & -0.534 & 1.313 & -0.031 & -0.407 & 0.685 \\
\hline
\end{tabular}

Dependent Variable: Growth in Market Share

H2e: IOE has a moderating effect on the relationship between judgmental FT and EV. When EV was regressed against the four elements of IOE and judgmental FT, ANOVA results, table 9, yielded coefficients of the variables, none of which was statistically significant. Sub-hypothesis $\mathrm{H} 2 \mathrm{e}$ was therefore, rejected and concluded that IOE does not have a moderating effect on the relationship between judgmental FT and EV.

Table 9 Internal Operating Environment - Coefficients

\begin{tabular}{|ll|l|l|l|l|l|}
\hline \multirow{2}{*}{ Model } & \multicolumn{2}{|l|}{$\begin{array}{l}\text { Un-standardized } \\
\text { Coefficients }\end{array}$} & $\begin{array}{l}\text { Standardized } \\
\text { Coefficients }\end{array}$ & \multirow{2}{*}{} \\
\cline { 2 - 4 } & Beta & Std. Error & Beta & t-Value & P-Value \\
\hline 1 & (Constant) & 1.445 & 0.819 & & 1.765 & 0.079 \\
& Leadership & -0.013 & 0.101 & -0.011 & -0.131 & 0.896 \\
& Strategy & 0.042 & 0.058 & 0.060 & 0.721 & 0.472 \\
& Structure, & -0.041 & 0.116 & -0.030 & -0.348 & 0.728 \\
& Culture & 0.109 & 0.131 & 0.066 & 0.835 & 0.405 \\
& Judgmental method & -0.061 & 0.067 & -0.080 & -0.923 & 0.357 \\
\hline
\end{tabular}

Dependent Variable: Expected Value

H2f: IOE has a moderating effect on the relationship between judgmental FT and ROS. ROS was used as a performance measure against the four elements of the IOE and judgmental FT. Table 10 yielded coefficients of the variables where the $p$-values of these variables revealed that none of them was statistically significant. Sub-hypothesis H2f was therefore, rejected and concluded that IOE does not have a moderating effect on the relationship between judgmental FT and ROS

Table 10 Internal Operating Environment - Coefficients

\begin{tabular}{|cl|l|l|l|l|l|}
\hline \multirow{2}{*}{ Model } & \multicolumn{2}{|l|}{$\begin{array}{l}\text { Un-standardized } \\
\text { Coefficients }\end{array}$} & \multicolumn{2}{l|}{$\begin{array}{l}\text { Standardized } \\
\text { Coefficients }\end{array}$} & \\
\cline { 2 - 5 } & Beta & Std. Error & Beta & t-Value & P-Value \\
\hline 1 & (Constant) & 11.766 & 4.308 & & 2.731 & 0.007 \\
& Leadership & -0.107 & 0.534 & -0.017 & -0.200 & 0.842 \\
& Strategy & -0.134 & 0.306 & -0.036 & -0.438 & 0.662 \\
& Structure, & -0.431 & 0.612 & -0.060 & -0.704 & 0.483 \\
& Culture & -0.041 & 0.689 & -0.005 & -0.059 & 0.953 \\
& Judgmental FT & 0.317 & 0.350 & 0.079 & 0.905 & 0.367 \\
\hline
\end{tabular}

Dependent Variable: ROS 
H2g: IOE has a moderating effect on the relationship between judgmental FT and ROA. ROA having been regressed against the four elements of IOE and judgmental FT yielded p-values in table 11 where none of them was statistically significant, where the level of significance is 0.05 . Sub-hypothesis H2g was therefore, rejected and concluded that IOE has no moderating effect on the relationship between judgmental FT and ROA.

Table 11 Internal Operating Environment - Coefficients

\begin{tabular}{|c|c|c|c|c|c|c|}
\hline \multirow{2}{*}{\multicolumn{2}{|c|}{ Model }} & \multicolumn{2}{|c|}{$\begin{array}{l}\text { Un-standardized } \\
\text { Coefficients }\end{array}$} & \multirow{2}{*}{\begin{tabular}{|l|}
$\begin{array}{l}\text { Standardized } \\
\text { Coefficients }\end{array}$ \\
\\
Beta \\
\end{tabular}} & \multirow[b]{2}{*}{ t-Value } & \multirow[b]{2}{*}{ P-Value } \\
\hline & & Beta & Std. Error & & & \\
\hline & (Constant) & 3.755 & 2.339 & & 1.606 & 0.110 \\
\hline & Leadership & 0.458 & 0.290 & 0.133 & 1.580 & 0.116 \\
\hline & Strategy & -0.178 & 0.166 & -0.088 & -1.074 & 0.284 \\
\hline & Structure, & -0.164 & 0.332 & -0.042 & -0.495 & 0.621 \\
\hline & Culture & -0.318 & 0.374 & -0.067 & -0.849 & 0.397 \\
\hline & Judgmental method & -0.213 & 0.190 & -0.096 & -1.119 & 0.265 \\
\hline
\end{tabular}

Dependent Variable: ROA

H2h: IOE has a moderating effect on the relationship between judgmental FT and GMS. Regression results in table 12 showed that none of the p-values of the variables was statistically significant, where the level of significance is 0.05 . Sub-hypothesis H2h was therefore, rejected and concluded that IOE has no moderating effect on the relationship between judgmental FT and GMS 
Table 12 Internal Operating Environment - Coefficients

\begin{tabular}{|ll|l|l|l|l|l|}
\hline \multirow{2}{*}{ Model } & \multicolumn{2}{|l|}{$\begin{array}{l}\text { Un-standardized } \\
\text { Coefficients }\end{array}$} & $\begin{array}{l}\text { Standardized } \\
\text { Coefficients }\end{array}$ & & \\
\cline { 3 - 5 } & & Beta & Std. Error & Beta & t-Value & \multirow{2}{*}{ P-Value } \\
\hline & (Constant) & 64.508 & 16.981 & & 3.799 & 0.000 \\
& Leadership & -2.462 & 2.104 & -0.099 & -1.170 & 0.244 \\
& Strategy & -0.023 & 1.205 & -0.002 & -0.019 & 0.985 \\
& Structure, & -2.345 & 2.413 & -0.083 & -0.972 & 0.333 \\
& Culture & -1.818 & 2.716 & -0.053 & -0.669 & 0.504 \\
& Judgmental method & 0.345 & 1.380 & 0.022 & 0.250 & 0.803 \\
\hline
\end{tabular}

Dependent Variable: Growth in Market Share

H2i: IOE has a moderating effect on the relationship between combined FT and EV. $\mathrm{EV}$ was used as a predictor variable which was regressed against the four elements of IOE and combined FT. Table 13 yielded p-values none of which was statistically significant. Sub-hypothesis H2i was therefore, rejected and concluded that IOE has no moderating effect on the relationship between combined FT and EV

Table 12 Internal Operating Environment - Coefficients

\begin{tabular}{|ll|l|l|l|l|l|}
\hline \multirow{2}{*}{ Model } & \multicolumn{2}{|l|}{$\begin{array}{l}\text { Un-standardized } \\
\text { Coefficients }\end{array}$} & \multicolumn{2}{l|}{$\begin{array}{l}\text { Standardized } \\
\text { Coefficients }\end{array}$} & & \\
\cline { 3 - 5 } & & Beta & Std. Error & Beta & t-Value & \multirow{2}{*}{ P-Value } \\
\hline 1 & (Constant) & 1.518 & 0.832 & & 1.826 & 0.070 \\
& Leadership & -0.025 & 0.101 & -0.021 & -0.252 & 0.801 \\
& Strategy & 0.051 & 0.057 & 0.072 & 0.893 & 0.373 \\
& Structure, & -0.063 & 0.113 & -0.046 & -0.557 & 0.578 \\
& Culture & 0.110 & 0.132 & 0.066 & 0.828 & 0.409 \\
& Combined method & -0.044 & 0.072 & -0.049 & -0.609 & 0.543 \\
\hline
\end{tabular}

Dependent Variable: Expected Value

H2j: IOE has a moderating effect on the relationship between combined FT and ROS. P-values of the regression analysis, table 14, indicated that none of the variables was statistically significant. Sub-hypothesis $\mathrm{H} 2 \mathrm{j}$ was therefore, rejected and concluded that IOE does not have a moderating effect on the relationship between combined FT and ROS.

Table 14 Internal Operating Environment - Coefficients

\begin{tabular}{|c|c|c|c|c|c|c|}
\hline \multirow{2}{*}{\multicolumn{2}{|c|}{ Model }} & \multicolumn{2}{|c|}{$\begin{array}{l}\text { Un-standardized } \\
\text { Coefficients }\end{array}$} & \multirow{2}{*}{$\begin{array}{l}\text { Standardized } \\
\text { Coefficients } \\
\text { Beta }\end{array}$} & \multirow[b]{2}{*}{ t-Value } & \multirow[b]{2}{*}{ P-Value } \\
\hline & & Beta & Std. Error & & & \\
\hline \multirow[t]{6}{*}{1} & (Constant) & 11.461 & 4.376 & & 2.619 & 0.010 \\
\hline & Leadership & -0.044 & 0.530 & -0.007 & -0.084 & 0.933 \\
\hline & Strategy & -0.183 & 0.300 & -0.050 & -0.611 & 0.542 \\
\hline & Structure & -0.310 & 0.594 & -0.043 & -0.523 & 0.602 \\
\hline & Culture & -0.029 & 0.697 & -0.003 & -0.042 & 0.967 \\
\hline & Combined method & 0.187 & 0.377 & 0.040 & 0.496 & 0.620 \\
\hline
\end{tabular}

Dependent Variable: ROS 
H2k: IOE has a moderating effect on the relationship between combined FT and ROA. Regressing ROA against the four elements of IOE and combined FT yielded results of analysis of variance whose p-values, table 15, were statistically not significant. Sub-hypothesis H2k was therefore, rejected and concluded that IOE does not have a moderating effect on the relationship between combined FT and ROA.

Table 15 Internal Operating Environment - Coefficients

\begin{tabular}{|c|c|c|c|c|c|c|}
\hline \multirow{2}{*}{\multicolumn{2}{|c|}{ Model }} & \multicolumn{2}{|c|}{$\begin{array}{l}\text { Un-standardized } \\
\text { Coefficients }\end{array}$} & \multirow{2}{*}{\begin{tabular}{|l|}
$\begin{array}{l}\text { Standardized } \\
\text { Coefficients }\end{array}$ \\
Beta \\
\end{tabular}} & \multirow[b]{2}{*}{ t-Value } & \multirow[b]{2}{*}{ P-Value } \\
\hline & & Beta & Std. Error & & & \\
\hline \multirow[t]{6}{*}{1} & (Constant) & 3.433 & 2.377 & & 1.444 & 0.151 \\
\hline & Leadership & 0.417 & 0.288 & 0.121 & 1.449 & 0.149 \\
\hline & Strategy & -0.125 & 0.163 & -0.061 & -0.766 & 0.445 \\
\hline & Structure, & -0.280 & 0.323 & -0.071 & -0.869 & 0.386 \\
\hline & Culture & -0.417 & 0.379 & -0.087 & -1.101 & 0.272 \\
\hline & Combined method & 0.147 & 0.205 & 0.057 & 0.720 & 0.473 \\
\hline
\end{tabular}

Dependent Variable: ROA

H2l: IOE has a moderating effect on the relationship between combined FT and GMS. GMS was used as a performance measure against the four elements of IOE and combined FT. Results of the analysis of variance in table 16 yielded p-values none of which was statistically significant. Sub-hypothesis H2l was therefore, rejected and concluded that IOE does not have a moderating effect on the relationship between combined FT and GMS.

Table 16 Internal Operating Environment - Coefficients

\begin{tabular}{|ll|l|l|l|l|l|}
\hline \multicolumn{2}{|c|}{} & \multicolumn{2}{|l|}{$\begin{array}{l}\text { Un-standardized } \\
\text { Coefficients }\end{array}$} & \multicolumn{2}{l|}{$\begin{array}{l}\text { Standardized } \\
\text { Coefficients }\end{array}$} & \\
\cline { 3 - 5 } & Beta & Std. Error & Beta & t-Value & P-Value \\
\hline 1 & (Constant) & 61.960 & 17.179 & & 3.607 & 0.000 \\
& Leadership & -2.388 & 2.082 & -0.096 & -1.147 & 0.253 \\
& Strategy & 0.012 & 1.176 & 0.001 & 0.010 & 0.992 \\
& Structure, & -2.362 & 2.332 & -0.083 & -1.013 & 0.313 \\
& Culture & -2.190 & 2.736 & -0.064 & -0.801 & 0.425 \\
& Combined method & 1.350 & 1.480 & 0.072 & 0.913 & 0.363 \\
\hline
\end{tabular}

Dependent Variable: Growth in Market Share (GMS)

\section{DISCUSSION}

Contrary to various assertions that the IOE had an influence on the APF, this study revealed that the IOE did not influence APF. This is possibly true in LMFs in Kenya due to the fact that leadership in LMFs chooses to maintain safe ground with regard to sales volume and price of their products in order to enhance and/or maintain their reputation with the board of directors and/or shareholders. This means that the formulation of strategy for the LMFs is manipulated to ensure leadership's ability and competence are not in doubt. The internal politics and manipulation of forecasts are inherently for self-preservation.

This study also revealed that in using a more scientific method of forecasting (objective method) a unit marginal change in the use of this technique resulted in a decline of about a unit in Return on Sales (ROS). However, since management's ability is not evaluated against ROS, very few LMFs take serious note of the interaction effect of the IOE on APF and how it can be kept in check. 


\section{References}

Adebanjo, D. and Mann, R. (2000): “Identifying Problems in Forecasting Consumer Demand in the Fast Moving Consumer Goods Sector”. Benchmarking: An International Journal, Vol. 7, No. 3, 2000, pp. 223-230.

Allen, R. F. and Kraft, C. (1987). 'The organizational unconscious', Morristown, NJ: Human Resources Institute. Aosa. E (1998), the leadership challenge facing Kenya Organizations, the accountant, January-March.

Bails, D. G. and Peppers, L. C. (1982), Business Fluctuations: Forecasting Techniques and Applications. PrenticeHall International, Hemel Hempstead (1982), 481 pp.

Berinato, S. (2010): Leading through a crisis, Harvard Business Review.

Berinato, S. (2001): "What went wrong at Cisco in 2001", CIO Magazine, August 1, 2001.

Child J. (1974) Comments on Reimann and Mansfield's ‘bureaucracy.' Administrative Science Quarterly, 19. 247 250 .

Fahy, J. and Smithee, A. (1999), "Strategic Marketing and the Resource Based View of the Firm”. Academy of Marketing Science Review, Vol. 1999, No. 10.

Fildes, R. and Hastings, R. (1994): The Organization and Improvement of Market Forecasting, Journal of the Operational Research Society, 45, 1-16.

Ford, J.D. \& Slocum, J.W. (1977) 'Environment, technology and the structure of organizations.' Academy of Management Review, 2, 561 - 575.

Fry, L.W. (1982) Technology - structure research: Three critical issues. Academy of Management Journal, 25, 532 $-551$.

Huff, R. and Sultan, M. (2014): Gross Margin and Organizational Effects of Poor Forecasting Accuracy. Johnson, G. and Scholes, K. (1984) Exploring Corporate Strategy, Prentice-Hall, Englewood Cliffs, NJ, USA.

Maull, R., Brown, P. and Cliffe, R. (2001) organizational culture and quality improvement, International Journal of Operations \& Production Management, Vol .21, No. 3, pp. 302-326.

Mintzberg, Henry, and James Brian Quinn. 1996. The Strategy Process: Concepts, Contexts, Cases. 3 Ed. Upper Saddle River, NJ: Prentice Hall.

Porter, M. E. 1996. What is Strategy? Harvard Business Review 74(November-December):61-78.

Robbins, S.P (2004). Organization theory structure, Design, and applications. Third Edition, practice-Hill of India. Sekaran, U (1992),'Research Methods for business': A skill Building Approach, John Wiley, NY.

Sleeth, R.G and Johnston, W.R (1996). 'The effective leader as a Link between tasks and people'. SAM Advanced Management Journal, 61 (2) 16-21.

Thompson, A.A and Strickland, A.J (1993) strategic Management: concepts \& cases, Richard, D. Irwin, Inc ,New York, $7^{\text {th }}$ edition.

Thompson J.D. (1967) Organizations in action. New York: McGraw-Hill.

Zahra, S.A, (1993): "New product innovation in established companies: Associations with industry and strategy variables”. Entrepreneurship: Theory \& Practice, Vol.18, Issue 2, p.47, winter.

Khandwalla, P. N. (1977): "Management Styles and Organizational Effectiveness".

Smith, C. D., and Mentzer, J. T. (2010): User Influence on the Relationship between Forecast Accuracy, Application and Logistics Performance.

Vecchio, R. P. and Appelbaum, S. H. (1995): Managing Organizational Behaviour, Dryden, Toronto, Chapters $10,19$. 